\section{Smaller is better}

Think size matters? When it comes to performing intraoral scans, it does.

Make sure you optimise patient comfort and achieve an accurate impression by choosing the CS 3600 intraoral scanner from Carestream Dental.

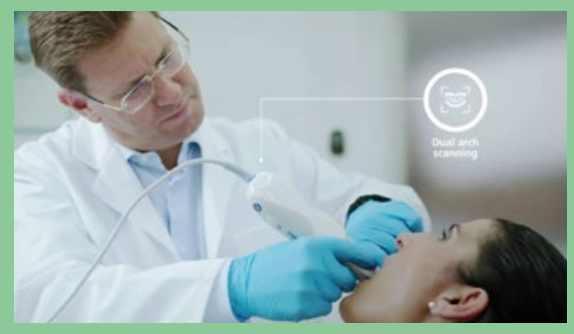

The scanner has a general tip which is ideal for normal scanning, an innovative side-orientated tip for hard to reach spaces, and a posterior tip for those with smaller mouths.

Add that to the fact that the tips are the smallest size on the market, and together these innovations mean that you can always treat every patient in absolute comfort.

Find out more by visiting stand E30.

For more information contact

Carestream Dental on 08001699692 or

visit www.carestreamdental.co.uk.

\title{
Grey's Anatomy Dental Scrubs from US to Launch in UK
}

The Grey's Anatomy style dental uniforms are already hugely popular in the US. Manufactured by Barco One Uniforms, they are renowned for their quality, comfort and appearance.

Bringing these scrubs across the North Atlantic, Diamond Designs now has exclusive distributor rights to the Grey's Anatomy range of uniforms in the UK and Ireland.

As such, professionals have an even greater choice of uniforms that offer elegance and durability, with a wide variety of colours available to complement each practice's individual branding.

Diamond Designs has more than 30 years of experience in designing, manufacturing and supplying first-class uniforms for the healthcare and beauty industries. To find out how you could upgrade your dental team's uniforms with a US favourite, don't miss Diamond Designs at the British Dental Conference and Dentistry Show 2019 on stand P72.

For more information, visit www. diamonddesignsuniforms.com or call 0845 0800576 .

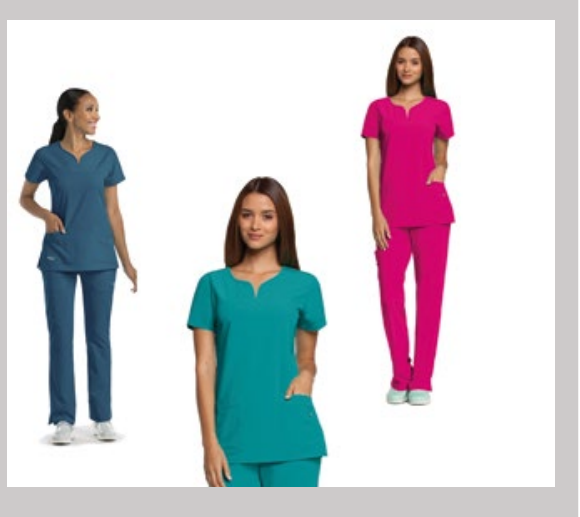

\section{A warm welcome}

Leading oral healthcare specialist Curaprox is looking forward to welcoming delegates to its stand at this year's British Dental Conference and

Dentistry Show 2019.

The friendly team will be showcasing a wide range of exciting products, including the ever-popular CS 5460 manual toothbrush, the CPS range of interdental brushes, as well as the colourful Be You range of toothpastes.

Amongst this year's offerings will be the new, cutting-edge Hydrosonic Ortho toothbrush, which has been innovatively designed to help patients optimise their oral healthcare regime.

Be sure to visit Curaprox at stand K50 to take advantage of exclusive offers on some of your favourite products.

For more information call 01480 862084, email info@curaprox.co.uk or visit www.curaprox.co.uk.
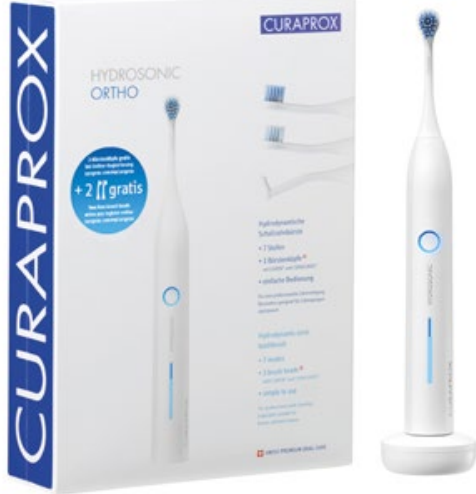

a team of legal experts who don't just have a detailed knowledge of employment law, but also specialise in the many issues related to running a dental practice.

Not having access to the right support can be costly and worst-case scenario, could put your business at risk from claims in an Employment Tribunal. Alternatively, on a positive note, if you get things right, you are more likely to have a happy and efficient team.

Visit stand K15 for more information.

Service, Oracle, designed specifically for

Clients using the Oracle service have unlimited access, via a telephone helpline, to 